\title{
Ospreys: The Revival of a Global Raptor
}

By Alan F. Poole. 2019. John Hopkins University Press. 205 pages, 39.95 USD, Cloth or E-book.

Many of us are familiar with the catastrophic declines in Bald Eagle (Haliaeetus leucocephalus) and Peregrine Falcon (Falco peregrinus) populations owing to DDT and their subsequent recovery in at least parts of their ranges. But many may not be aware of the extent to which Osprey (Pandion halieatus) were similarly affected. Alan

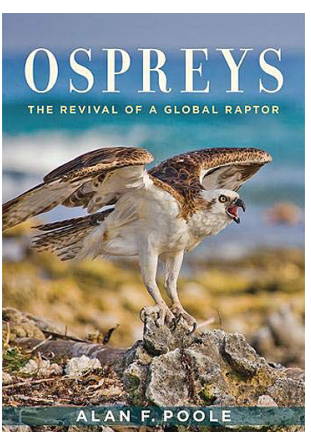
Poole is clearly an authority on the subject, having studied Ospreys in New England for over 35 years and authoring numerous scientific publications on the subject.

The title of this new offering is a bit of a misnomer, however, as the book covers a lot more ground than just the recovery of the species. An initial Introduction sets the stage and "A Hawk that Fishes" (Chapter 2) describes the Osprey's morphological adaptions, including differences among subspecies. The "Geography of Ospreys" (Chapter 3) summarizes the status of different Osprey populations across its global range, including Canada (citing several provincial atlassing efforts). Subsequent chapters cover foraging ecology, nesting behaviour, and migration, with the final two chapters discussing threats and solutions and the future outlook for Osprey. With such a cosmopolitan species and the breadth of topics he touches upon, Poole has done an admirable job constructing a cohesive narrative.

Poole's new book also brings into the discussion technological advances such as satellite telemetry, geolocators, and DNA evidence that have helped further our understanding of Ospreys over the last 30 years. Clearly willing to share the credit, he includes sidebar profiles on other Osprey researchers-reminding us how it takes a global village to understand this wide-ranging raptor. He also mentions where our understanding of Osprey is lacking, such as the period when young Osprey are learning to forage and during their first migration. I would like to have learned what factors exclude Osprey from breeding in tropical South America and Africa, given they overwinter there and reside year-round in Australia - but perhaps that will have to wait for Poole's next book.

Scientific chops notwithstanding, Poole's very readable prose makes it accessible for the layperson despite the quantity of information presented. For example, when discussing Osprey learning to fly, he remarks "As any human pilot will tell you - flying is easy; it's the landings that are tough" (p. 104) and mentions how human mothers with a houseful of rowdy teenagers might sympathize with female Ospreys at the nest. The book also benefits from over 100 excellent, decent-sized photographs and illustrations of Ospreys and their habitats, covering all manner of behaviour. Well laid-out maps showing Osprey movement patterns (from telemetry data) and several charts add to the fantastic visuals. On a very minor note, it would have been informative to have a density map of breeding Osprey in North America, but perhaps there are insufficient data. More Canadian content (and calling Nunavut a territory rather than a province on p. 44) would also have been welcome, but I suppose one can only ask so much with a global raptor. I do wish however, that all species names be capitalized or none; for example, Osprey is capitalized but Black Caiman and Agami Heron are not (p. 133).

My first childhood encounter with Ospreys was watching one catch a fish in a northern Ontario lake, only to see it lost to a marauding Bald Eagle. Since then, despite being a professional biologist, I have learned woefully little about this remarkable raptor. Ospreys: The Revival of a Global Raptor has greatly helped me address such gross negligence. I thoroughly enjoyed reading it and would highly recommend it to both novice naturalist and experienced birder alike.

Robert F. Foster

Northern Bioscience, Thunder Bay, ON, Canada 